\title{
¿Es la licitación pública la regla de general aplicación en contratación administrativa?
}

\section{Is public bidding the ordinary administrative contracting procedure?}

En este trabajo, el autor analiza si la licitación pública es procedimiento administrativo general y obligatorio para celebrar contratos administrativos o la Administración del Estado puede discrecionalmente elegir con quién y cómo contrata, y determinar a su arbitrio el procedimiento de selección del futuro contratista. En este sentido, se estudian los procedimientos de licitación pública, licitación privada y trato directo, con la finalidad de determinar los requisitos y condiciones que les permiten a los órganos públicos elegir el tipo de procedimiento de selección de oferentes.

Palabras clave: Licitación Pública, Licitación privada, Trato directo.
In this work, the author analyzes whether public bidding is a general and compulsory administrative procedure to enter into administrative contracts or the State Administration can discretionally choose who and how it contracts and determine at its discretion the selection procedure of the future contractor. In this sense, the procedures of public bidding, private bidding and direct negotiation are studied, with the finality of determining the requirements and conditions that allow public bodies to choose the type of bid selection procedure.

Keywords: Public Bidding, Private bidding, Direct treatment.

\section{Introducción}

El año 2001, dos ilustres administrativistas nacionales discutían sobre cuál era el procedimiento administrativo general y obligatorio para

\footnotetext{
* Doctor en Derecho. Profesor de Derecho Administrativo. Universidad de los Andes, Santiago, Chile. Dirección postal: Mons. Álvaro del Portillo 12.455, Las Condes, Santiago. Correo electrónico: jcflores@miuandes.cl.

Este trabajo forma parte del Proyecto Fondecyt de Iniciación N¹1180639, "Recepción del principio de equilibrio económico y financiero en los contratos administrativos de suministro y prestación de servicios, de construcción de obra pública y de concesión de obra pública", del que el autor es investigador principal.
}

Artículo recibido el 27 de noviembre de 2019 y aceptado el 14 de mayo de 2020. 
formar la voluntad contractual y celebrar contratos administrativos. La discrepancia dogmática se fundaba en el Dictamen $N^{\circ} 46.532$, de 2000, de la Contraloría General de la República, y se discutía si la Administración Pública debía contratar siempre mediante licitación pública y, en consecuencia, solo en casos excepcionales y justificados podía acudir a la licitación privada o a la contratación vía trato directo, o si existía una especie de discrecionalidad en la selección del procedimiento administrativo por razones de eficiencia y eficacia, pudiendo prescindir de la licitación pública y optar libremente por la licitación privada o por el trato directo.

Por una parte, Rolando Pantoja señalaba que el artículo 8 bis de la Ley Orgánica Constitucional de Bases Generales de la Administración del Estado $N^{\circ}$ 18.575, modificada por la Ley $N^{\circ} 19.653$ sobre probidad administrativa, habilitaba a la Administración del Estado para seleccionar el procedimiento de contratación administrativa sin que existiese un orden predeterminado para la formación de la voluntad contractual, fundado en razones de eficiencia y eficacia ante los mayores costos y desgaste de recursos que involucra la licitación pública'. Por otra parte, Jorge Precht argumentaba que dicho precepto -artículo 8 bis-, consagraba la idea de la licitación pública como regla general, por cuanto se establecía que la procedencia de la licitación privada y el trato directo solo tendría lugar solo cuando existiese previa resolución fundada que así lo dispusiese ${ }^{2}$.

La inexistencia de una ley general de contratos públicos, como ocurre en otros ordenamiento jurídicos, como el español con la Ley $N^{\circ}$ 9/2017, de 8 de noviembre, de Contratos del Sector Público, o el colombiano con la Ley $N^{\circ}$ 80, de 1993, sobre el Estatuto General de Contratación de la Administración Pública, ha permitido que el artículo 9 de la Ley $N^{\circ} 18.575$, adquiera el carácter de norma basal para determinación de los procedimientos administrativos de contratación pública, siendo permanentemente invocado cuando se tratase de contrataciones desprovistas de una norma legal especial.

Sin embargo, dicho precepto es necesario analizarlo a la luz de las leyes especiales que regulan los denominados contratos administrativos típicos, esto es, el contrato de obra pública regulado por el DS $N^{\circ} 75$, de 1 de diciembre de 2004, del Ministerio de Obras Públicas, el contrato de concesión de obra pública regulado por el DS N 900, de 18 de diciembre de 1996, del Ministerio de Obras Públicas, que fija el texto refundido, coordinado y sistematizado del DFL MOP N 164, de 1991, Ley de Concesiones de Obras Públicas, y finalmente la Ley $N^{\circ} 19.886$, de 2003, de Bases sobre Contratos Administrativos de Suministro y Prestación de Servicios, que consagran reglas especiales sobre los procedimientos administrativos de licitación pública, licitación privada y trato directo, específicando sus causales, procedencia e

\footnotetext{
1 PANTOJA 2001, 5.

2 PRECHT 2001, 5. En un sentido similar, Aróstica señalaba que el artículo 9 disponía un sistema de prelación de procedimientos. Aróstica 2002, 305.
} 
incluso relegando la licitación pública a supuestos excepcionales, como en el caso de los convenios marcos.

Sin duda con la entrada en vigencia de la Ley $N^{\circ} 19.886$ de 2003, de Bases sobre Contratos Administrativos de Suministro y Prestación de Servicios, se consagró una regla similar a aquella dispuesta en el artículo 9 de la Ley $\mathrm{N}^{\circ}$ 18.575, describiendo los tres clásicos procedimientos de selección de contratista privado, pero condicionando la procedencia de la licitación pública principalmente a la cuantía del futuro contrato. En efecto, el artículo 5 dispuso expresamente que la Administración adjudicará los contratos que celebre mediante licitación pública, licitación privada o contratación directa, y que la licitación pública será obligatoria cuando las contrataciones superen las 1.000 unidades tributarias mensuales, salvo lo dispuesto en el artículo $8^{\circ}$ de la misma ley, que se refiere a los casos en los cuales la Administración puede acudir a licitación privada o trato directo. Todo ello, sin perjuicio de la incorporación mediante el artículo 30 letra d) de la Ley $N^{\circ} 19.886$, y de los artículos 14 y siguientes del Reglamento, de los convenios marcos como un tipo de contratación administrativa que altera lo dispuesto por el artículo 9 de la Ley $N^{\circ} 18.575$.

Ahora bien, las reglas anteriores contenidas en la Ley $N^{\circ} 19.886$, de conformidad con el artículo 3 letra e) han sido interpretadas por la jurisprudencia de la Contraloría como normas comunes aplicables a otros contratos administrativos $^{3}$, principalmente de obras públicas ${ }^{4}$. No obstante, esta especie de supletoriedad, si se interpretase en términos exegéticos, arrojaría que la Ley $N^{\circ} 19.886$, de 2003, solo sería aplicable en los casos que estemos frente a contratos administrativos típicos o nominados, mientras que en los contratos innominados, cuya regulación es tenue o inexistente en materia de procedimientos de selección del contratista, podría la Administración del Estado argumentar que ostenta un margen de discrecionalidad para seleccionar el procedimiento administrativo más adecuado a la naturaleza del contrato público entre licitación pública, privada o trato directo.

Habiendo transcurrido más de una década de aquella disputa doctrinal, y sin perjuicio de los avances legales, dogmáticos y jurisprudenciales, consideramos que actualmente la interrogante sigue vigente ¿Es la licitación pública el procedimiento común de formación de la voluntad contractual o la Administrativa ostenta una especie de discrecionalidad para seleccionar el procedimiento administrativo que mejor se adecue al contrato y a los recursos que dispone en un momento determinado? Esta pregunta, hoy es esencial para una adecuada interpretación de las causales que permiten sortear la licitación pública, en favor de la licitación privada o el trato directo.

Dicha interrogante encuentra su fundamento en la amplitud de algunas causales de licitación privada y trato directo que potencialmente permiten

\footnotetext{
3 Dictamen $N^{\circ} 53.520$ (2008).

4 Dictamen No 38.794 (2009).
} 
excluir la licitación pública en favor de contrataciones públicas sin concursabilidad directa. Sin embargo, es preciso rescatar que la incorporación de parámetros objetivos, como los montos para determinar la procedencia de la licitación pública, ha constituido un enorme avance respecto de los supuestos fácticos consagrados, por ejemplo en el artículo 86 del DFL Nº 850, de 1998, del Ministerio de Obras Públicas, que fija el texto refundido, coordinado y sistematizado de la Ley $N^{\circ} 15.840$, de 1964 y del DFL No206, de 1960, que contiene la ley orgánica del Ministerio de Obras Públicas.

El presente trabajo tiene por objeto analizar y comprobar que la licitación pública es el procedimiento general de contratación administrativa, y que las causales de licitación privada y trato directo, en la forma en que se encuentran reguladas potencialmente pueden transformar a la licitación privada o el trato directo en procedimientos administrativos de general aplicación.

Proponemos que existen causales de licitación privada, y principalmente de trato directo, estrictas y tasada, que responden a situaciones fácticas excepcionales, como emergencias o ausencia de licitantes, o se sujetan a determinados rangos numéricos para reducir al mínimo cualquier grado de discrecionalidad. Sin embargo, también llegamos a la conclusión que existen otras causales de licitación privada y trato directo que amplían la discrecionalidad de la Administración contratante, y que merecen ser revisadas, a la luz del principio de transparencia y de motivación suficiente, por cuanto no son armónicas con un Estado de Derecho moderno.

\section{Licitación pública como procedimiento administrativo}

Si bien, a priori no existe una postura determinante que justifique la elección de la licitación pública como procedimiento administrativo general en la contratación administrativa, existen razones jurídicas importantes que justifican la elección de la licitación pública como el procedimiento administrativo más adecuado para resguardar la igualdad ante la ley, la libre participación de todas las personas en la participación de los bienes públicos y la publicidad y probidad del actuar público.

A nuestro juicio, las razones jurídicas que motiva al Estado a licitar son diversas y responden a que el Estado puede servirse de los privados en la satisfacción de las necesidades públicas inspirado en el principio de subsidiaridad, entregando a los particulares aquellas actividades que el Estado no puede realizar en términos eficientes y eficaces. Lo cual habilita a los privados a participar en igualdad de oportunidades en la vida nacional, con el objetivo de lograr la mayor realización espiritual y material posible.

En primer lugar, el contrato administrativo como una instancia de colaboración público-privada, implica la configuración de situaciones de privilegios, a favor de aquel particular que es invitado por el Estado a desarrollar y/o explotar una obra pública o un servicio público, como en el caso de los contratos de concesión de obra o de servicio público, en que el concesio- 
nario presta servicios básicos de primera necesidad contra una tarifa o peaje regulado.

Es precisamente la atribución de esa situación de privilegio, que de conformidad con el artículo 1 inciso $5^{\circ}$, sobre igual participación en las personas en la vida nacional, y los números 2, 20 y 22 del artículo 19 de la Carta Fundamental, exigen determinar reglas equitativas entre aquellos que, invitados por el Estado, pretenden ser partícipes activos en la satisfacción indirecta de necesidades públicas, para que el Estado pueda justificar legítimamente la asignación de dichos beneficios a unos en perjuicios del resto de los miembros de la comunidad, sin infraccionar el principio de igualdad ante la ley.

Lo anterior se puede apreciar en el artículo $1^{\circ}$ del DS N 900, de 18 de diciembre de 1996, del Ministerio de Obras Públicas, que dispone que el ámbito específico de la concesión de obra pública es la ejecución, reparación y mantención de una obra pública fiscal. Por su parte, el artículo 3, numerales 14 y 15 del DS $N^{\circ} 75$, de $1^{\circ}$ de diciembre de 2004, del Ministerio de Obras Públicas, que dispone que en el caso de los contratos de construcción de obra pública, esta es entendida como cualquier inmueble, de propiedad del Estado, construido, reparado o conservado por terceros mediante un contrato administrativo. En ambas normas, se hace referencia a un bien inmueble fiscal -de propiedad del fisco- que a través de un contrato administrativo específico se entrega a un particular de manera exclusiva y excluyente para ser ejecutado, reparado y conversado por un particular contra un precio determinado.

Por su parte, en el caso de aquellos contratos que no implican la configuración de una situación de privilegio ni una transferencia de una posición jurídica determinada, sino que conllevan el suministro de bienes y servicios del mundo privado hacia el Estado, son los principios de igualdad ante la ley y la no discriminación arbitraria del Estado en materia económica los que lo obligan a fijar reglas uniformes que permitan una equivalente y armoniosa participación de los interesados en contratar con el Estado 5 .

Una segunda razón jurídica para licitar, junto con establecer reglas claras, precisas y objetivas, es una exigencia del principio de probidad, que obliga al Estado -incluso en actuaciones bilaterales- a privilegiar el interés general por sobre el particular. De esta forma, la probidad obliga a los órganos públicos a configurar procedimientos administrativos concursales que permitan la igual participación de los ciudadanos en el bienestar nacional, eliminando cualquier tipo de cláusula que busque privilegiar los intereses específicos de uno de los contratistas sin una explicación que sea ajena al interés general.

La probidad administrativa en materia de contratación pública es exigida por la aplicación general del artículo $8^{\circ}$ de la Carta Fundamental, que

5 Boquera 1963, 11 y 12. 
obliga a los titulares de la función pública a dar estricto cumplimiento al principio de probidad en todas sus actuaciones sin distinción alguna. A su vez, por los artículos 52 y 53 de la Ley No 18.575, Orgánica Constitucional de Bases Generales de la Administración del Estado, que obligan a los funcionarios partícipes de la licitación pública a observar una conducta funcionaria intachable y un desempeño leal y honesto de la función o cargo. Mientras que, el segundo precepto dispone que el interés general, que es la finalidad del principio de probidad, exige el empleo de medios idóneos de diagnóstico, decisión y control, y su prevalencia se expresa en el recto y correcto ejercicio del poder, en lo razonable e imparcial de las decisiones administrativas y en la integridad ética y profesional de la administración de los recursos públicos que gestiona.

Sin embargo, también el principio de probidad administrativa en la contratación pública tiene expresas y específicas manifestaciones en el artículo 4 de la Ley $N^{\circ} 19.886$, y en los artículos $4^{\circ}, 5$ bis y 104 bis del DS N²50, de 24 de septiembre de 2004 que contiene el Reglamento de Compras Públicas. Una mención especial tiene la disposición 6 bis del mismo reglamento, que obliga a los funcionarios a abstenerse de participar en los procedimientos de contratación regulados por la Ley $N^{\circ} 19.886$, de 2003, cuando exista cualquier circunstancia que les reste imparcialidad, en los términos del artículo 62, N6, de la Ley N 18.575 Orgánica Constitucional de Bases Generales de la Administración del Estado.

Una tercera razón jurídica para licitar se relaciona con el margen de discrecionalidad para decidir qué ostenta la Administración del Estado ${ }^{6}$, y el adecuado ejercicio de las potestades públicas, que exige la existencia de un procedimiento racional y justo que sirva de sustento formal y sustancial para limitar la posibilidad que el Estado contrate con quiera, sin sujeción a reglas mínimas de eficiencia. Tal como señala Moraga, la Administración no tiene posibilidad de elegir libremente con quien contrata, sino que debe hacerlo con aquellos contratistas que le entreguen a la Administración del Estado la mejor combinación entre beneficios y gastos ${ }^{7}$.

Aclarado lo anterior, debemos señalar que la licitación pública ha sido conceptualizada por Dromi como "(...) el procedimiento administrativo de preparación de la voluntad contractual, por el que un ente público en ejercicio de la función administrativa invita a los interesados para que, sujetándose a las bases fijadas en el pliego de condiciones, formulen propuestas de entre las cuales seleccionará y aceptará las más conveniente" 8 . Por su parte, Aróstica ha señalado que la licitación pública es una especie de procedimiento administrativo de carácter concursal y abierto, compuesto por una sucesión ordenada de actos unilaterales emanados de la Administración de

\footnotetext{
6 Díz 2012, 105.

7 Moraga 2019, 317.

8 DROMI 2010, 76.
} 
los particulares interesados, y cuya finalidad es la adjudicación y posterior celebración del respectivo contrato?.

Normativamente, el artículo 7 letra a) de la Ley $N^{\circ}$ 19.886, de 2003, define licitación pública como un procedimiento administrativo de carácter concursal mediante el cual la Administración realiza un llamado público, convocando a los interesados para que, sujetándose a las bases fijadas, formulen propuestas, de entre las cuales seleccionará y aceptará la más conveniente. Por su parte, el artículo $4 \mathrm{~N}^{\circ} 25$ del DS N 75, de 2004, del Ministerio de Obras Públicas, que regula el contrato de construcción de obra pública, señala que la licitación es el procedimiento mediante el cual se solicitan a los proponentes inscritos en el Registro de Contratistas del Ministerio de Obras Públicas o precalificados, si es el caso, cotizaciones para la ejecución de una obra pública. La misma idea se encuentra consagrada en los artículos 4 y siguientes de la Ley de Concesiones de Obras Públicas, como en el artículo 14 del su reglamento, contenido en el DS N 956, 2 de marzo de 1999, del Ministerio de Obras Públicas.

De lo anterior, se pueden extraer algunas reglas básicas que nos permiten moldear las características que hacen que la licitación pública se constituya como una regla general en materia de contratación administrativa. En primer lugar, es un procedimiento administrativo, es decir, una sucesión de actos trámites vinculados entre sí, emanados tanto de la Administración Pública, como de los particulares, que tiene por objetivo la dictación del acto administrativo terminal consistente en la adjudicación o suscripción del contrato con la debida toma de razón, según sea el caso ${ }^{10}$.

El hecho de circunscribir la licitación pública dentro del marco de los procedimientos administrativos hace que su naturaleza jurídica exceda a cada acto administrativo individual, distinguiéndose por constituir una secuencia, ordenada y metódica de diversos estadios, cada uno de los cuales tiene su contenido propio. De este modo, asumir que la licitación pública es un procedimiento administrativo implica tornar aplicable a su respecto los principios propios de éste, tales como transparencia, no formalización, celeridad, teniendo en consideración las particularidades y principios específicos de la licitación ${ }^{11}$.

Una segunda regla importante, es determinar que la licitación no es un simple procedimiento administrativo como cualquier otro, sino que un procedimiento concursal mediante el cual la Administración Pública somete a su escrutinio las ofertas de los licitantes para administrar la existencia de bienes escasos o de situaciones de privilegio en la forma más conveniente posible

\footnotetext{
9 Aróstica 2006, 292.

10 Constructora e Inmobiliaria Amulen SpA con Ministros de la Corte de Apelaciones de Santiago (2019).

11 Comadira 2000, 6.
} 
al bien común. Así lo ha señalado el Tribunal de la Contratación Pública afirmando que:

"La licitación pública constituye un procedimiento, en que se desarrollan una serie o sucesión de actos, tanto de la entidad licitante, como de los oferentes que tienen como propósito, concluir en un acto terminal, y en consecuencia todas actuaciones, responden a un orden prestablecido, publicación de las bases de licitación, recepción de las ofertas, apertura de las ofertas, evaluación de éstas, hasta la dictación del acto terminal que es la adjudicación o declaración de deserción, conforme a la lógica del procedimiento y que se debe ejecutar dentro de tiempos determinados"12.

De esta forma, la concursabilidad se justifica en la igualdad de acceso de las personas a los bienes del Estado, y en las exigencias de transparencia y publicidad que exige tanto el artículo $8^{\circ}$ de la Carta Fundamental y la Ley N²0.285, de 2008, sobre acceso a la información pública.

\section{La licitación pública procedimiento general de contratación}

Las razones jurídicas antes esgrimidas junto con garantizar la igualdad, publicidad, transparencia y probidad en la gestión de los bienes públicos permiten mantener una adecuada competitividad entre los distintos contratantes presentes en la licitación, y que nos permite afirmar que la licitación pública es el procedimiento administrativo general de contratación administrativa.

Lo anterior, también ha sido discutido a nivel comparado. De esta manera, la doctrina transandina explica que la licitación pública es la regla general para todo tipo de contratación administrativa, porque mediante ella se asegura la legalidad, moralidad, convivencia y limitación de la discrecionalidad de los agentes públicos intervinientes ${ }^{13}$. Así Comadira, sustenta que la Administración del Estado cuando contrata debe seleccionar, en sentido de que al elegir al contratista debe preservar la moralidad de su accionar, la eficacia de la gestión y el trato igualitario a quienes estén, objetivamente, en condiciones de aspirar a la contratación ${ }^{14}$. Aunque, también existen posiciones que señalan que la Administración goza de discrecionalidad para elegir un procedimiento administrativo de selección directo o más reglamentario que la licitación pública ${ }^{15}$.

Por su parte, la doctrina española se inclina por considerar la licitación pública o procedimiento abierto como de aplicación general, salvo que la ley disponga expresamente la utilización de otro procedimiento de adjudica-

12 Sentencia TCP Rol No 116 (2013).

13 Marienhoff 1993, 280.

14 Comadira 2000, 15.

15 Cassagne 1999, 43 y 44. 
ción ${ }^{16}$. Lo anterior ha sido recogido expresamente en el artículo 131.2 de la Ley $N^{0}$ 9/2017, de 8 de noviembre, de Contratos del Sector Público ${ }^{17}$.

Por su parte, el artículo 24 de la Ley N 80, de 1993, sobre el Estatuto General de Contratación de la Administración Pública de Colombia, señala que la elección del contratista se efectuará siempre a través de licitación o concurso público, salvo que se acuda a contratación directa. A su vez, las actuaciones de las autoridades serán públicas y los expedientes que las contengan estarán abiertos al público, debiendo los actos administrativos que se expidan en el marco de la licitación ser motivados en forma detallada y precisa, al igual que los informes de evaluación, el acto de adjudicación y la declaratoria de desierto del proceso de elección.

Volviendo a nuestro país, a nivel normativo la elección de la licitación pública como procedimiento administrativo general de formación de la voluntad contractual, se encuentra condicionada, por una parte por la cuantía del contrato, y por otra parte, por determinadas situaciones fácticas que habilitan a la Administración a prescindir de la licitación pública como regla general en beneficio de la eficiencia y eficacia de la contratación. Así, el artículo 5 de la Ley $N^{\circ}$ 19.886, dispone que la licitación pública será obligatoria cuando las contrataciones superen las 1.000 unidades tributarias mensuales. De este precepto se podría extraer la siguiente regla consistente en que la licitación pública solo es obligatoria en las contrataciones cuyo monto supere las 1.000 unidades tributarias mensuales, quedando la autoridad facultada para seleccionar un procedimiento administrativo diferente de la licitación pública respecto de montos inferiores a dicha cantidad. Sin embargo, el artículo $8^{\circ}$ de la misma ley, cuyas normas son reiteradas y desarrolladas en el artículo 10 del Reglamento, establece que la licitación privada y el trato directo procederán únicamente en determinados casos. De esta manera, aun cuando la contratación sea inferior a 1.000 UTM, será igualmente obligatorio recurrir a la licitación pública, salvo que sea imprescindible un contratación eficaz y eficiente, mediante la licitación privada o el trato directo.

También ratifica que la licitación pública es el procedimiento general de contratación, la prohibición establecida en el artículo 7 de la Ley $N^{\circ} 19.886$, y en el artículo 13 del DS N²50, de 2004, Reglamento de Compras Públicas, de no fragmentar las contrataciones públicas con el propósito de variar el procedimiento de contratación. De esta forma, la norma impide que por vía de la reducción artificial del monto de un contrato administrativo bajo las 1.000 UTM, se sortee las garantías de concursabilidad que ofrece la licitación pública.

\footnotetext{
16 Santamaría 2018, 192.

17 "La adjudicación se realizará, ordinariamente utilizando una pluralidad de criterios de adjudicación basados en el principio de mejor relación calidad-precio, y utilizando el procedimiento abierto o el procedimiento restringido, salvo los contratos de concesión de servicios especiales del Anexo IV, que se adjudicarán mediante este último procedimiento".
} 
Así lo ha señalado recientemente la Contraloría General de la República, que a propósito del Mercado Público exige una explicación razonada de la entidad licitante cuando decide no someter las compras superiores a 1.000 UTM al proceso de grandes compras regulado en el artículo 14, en lo relativo con emergencias, urgencias o imprevistos. Así, la Contraloría de la República en dichos casos exige una resolución fundada del jefe superior del servicio ${ }^{18}$.

Respecto de las situaciones que permiten que la Administración del Estado, pueda prescindir de la licitación pública, éstas son trasversales y se encuentran reguladas tanto en contratos administrativos asociados a la infraestructura pública, por ejemplo en el artículo 86 de la ley orgánica del Ministerio de Obras Públicas al cual se remite el DS N 75, de 2004, del mismo ministerio, que contiene el contrato de obra pública para determinar la excepciones a la licitación pública (v.gr., emergencias, único proveedor, contrato resuelto, etc.). Así como también, en los contratos de suministro y prestación de servicios, que como se verá, regula los supuestos tradicionales para excluir la licitación pública, aunque con algunas situaciones configuradas en términos excesivamente amplios -la confianza en el proveedor- que pueden dar lugar a la postergación artificial de la licitación pública.

Lo anterior es coherente con el principio de libre concurrencia, recogido normativamente en el inciso $2^{\circ}$ del artículo 9 de la Ley $N^{\circ} 18.575$, que busca que las ofertas de todos los proponentes que han cumplido con los pliegos de condiciones no sean excluidas a priori, por errores intranscendentes o no esenciales. En efecto, mientras más numerosas sean las ofertas válidas que concurran a una licitación, mayor es el ámbito de acción de la Administración para elegir la propuesta más satisfactoria al interés público, en la medida naturalmente, que no se transgredan los principios de estricta sujeción a las bases y de igualdad de los licitantes ${ }^{19}$, por cuanto la libre concurrencia y la selectividad de las ofertas más convenientes deben someterse a una concursabilidad objetiva y transparente ${ }^{20}$.

De esta forma, son reñidas por nuestro ordenamiento jurídico prácticas administrativas que mediante la utilización del ordenamiento jurídico evitan acudir a la licitación pública. Así, la Contraloría General de la República ha declarado no ajustada a derecho cláusulas de renovación automática de contrato con el objetivo de mantener una determinada materia alejada del sistema de concurso público ${ }^{21}$. En la misma línea, a nivel de libre competencia, la Corte Suprema ha calificado como contraria al ordenamiento nacional la renovación constante de contratos de servicios de transporte por el conce-

\footnotetext{
18 Dictamen N 14.236 (2018). Cabe señalar, que recientemente la Contraloría General de la República ha dictado una nueva normativa sobre el trámite de toma de razón, alterando los montos legales y de esta forma hacer aleatorio el control de la selección del procedimiento de contratación pública. Vid., Resolución Nº (2019).

19 Dictamen $N^{\circ} 42.621$ (2007).

20 Abarca 2013, 326.

21 Dictamen No 81.434 (2015).
} 
sionario de un aeropuerto en perjuicio de la licitación pública que permitiría el ingreso de nuevos competidores en el servicio de transportes de pasajeros desde y hacia el aeropuerto ${ }^{22}$.

\section{Licitación pública restringida o condicionada}

Si bien uno de los principios relevantes de la licitación pública es la transparencia y libre concurrencia de los oferentes al Ilamado público, según lo dispuesto en el artículo 8 bis de la Ley $N^{\circ} 18.575$, con el objetivo de asegurar al Estado la mayor cantidad de ofertas el proceso de licitación, el legislador por razones de eficacia y de buena administración permite limitar la posibilidad que cualquier persona pueda participar en los procesos licitatorios, con la finalidad de diagnosticar, en términos objetivos, la experiencia y seriedad entre los licitantes, evitando la ofertas temerarias que durante la ejecución del contrato generen mayores costos para el Estado.

Lo anterior se puede detectar tanto en la construcción de obra pública, concesiones de obras públicas y en el suministro y prestación de servicio, donde el legislador establece barreras específicas para filtrar a los potenciales licitantes y asegurar la seriedad y eficacia del futuro contrato administrativo. En primer lugar, si analizamos la Ley $N^{\circ} 19.886$, de 2003, podemos apreciar que la libre concurrencia se encuentra limitada solo a los potenciales oferentes del Estado, que de conformidad con el artículo 16 de esa normativa se encuentren inscritos en una registro electrónico oficial de contratistas de la Administración, a cargo de la Dirección de Compras y Contratación Pública, y que no tengan una causal de inhabilidad para contratar con el Estado ${ }^{23}$.

La exigencia anterior ha sido reiterada por la jurisprudencia de la Contraloría, que considera que la exigencia de inscripción en el registro electrónico oficial de contratistas de la Administración solo puede requerirse por los organismos para efectos de celebrar el respectivo contrato, cuando así lo establezcan en las bases que regulen la licitación, sin que resulte pertinente disponer tal inscripción para participar en esta clase de convocatorias ${ }^{24}$.

Una idea similar encontramos en el inciso $2^{\circ}$ del artículo $1^{\circ}$ del DS $N^{\circ} 75$, de 2004, del Ministerio de Obras Públicas, que regula el Reglamento para Contratos de Obra Pública, que limita la licitación, adjudicación y suscripción de los contratos de construcción de obras públicas del Ministerio de Obras Públicas, solo a los contratistas inscritos en los registros del Ministerio que se determinen en las bases administrativas ${ }^{25}$.

\footnotetext{
22 Delfos Ltda., con SCL (2008).

23 El artículo 81 del DS N²50, de 2004, del Ministerio de Hacienda, señala que el objeto del registro de proveedores es registrar y acreditar antecedentes, historial de contratación con las entidades, situación legal, financiera, idoneidad técnica, así como la existencia de las causales de inhabilidad, para contratar con las entidades.

24 Dictamen $N^{\circ} 76.516$ (2012).

25 El artículo 6 del DS N 75 señala que corresponde a la Dirección General de Obras Públicas la administración de los registros de contratistas. Por su parte, el artículo $5^{\circ}$ señala que el Registro
} 
Finalmente, confirma nuestra afirmación las normas modificatorias introducidas por la Ley $N^{\circ}$ 20.410, de 2010, al DS No 900, de 1996, del Ministerio de Obras Públicas, que establece la Ley de Concesiones de Obra Pública, en el artículo 6 bis habilita al Ministerio de Obras Públicas para efectuar un llamado a precalificación de los licitantes, con el objetivo de seleccionar a los interesados que cumplan con los requisitos uniformes, objetivos y razonables que se establezcan en las respectivas bases de precalificación, los que solo podrán referirse a aspectos jurídicos, de capacidad financiera o técnica, de experiencia, entre otros aspectos.

Como se puede apreciar, el principio de libre concurrencia se morigera en materia licitatoria, cuando el objeto contractual se relaciona con proyectos importantes de infraestructura pública -concesiones o construcción de obras públicas- o cuando por la densidad de las compras públicas, es necesario tener certeza jurídica sobre la capacidad económica y la seriedad del potencial licitante, lo que nos lleva a preguntarnos ¿si la licitación pública es la regla general de contratación administrativa, y la imposición de registros públicos o de procesos de precalificación, no constituye un atentado a que la licitación pública garantice el principio de igualdad, concurrencia y transparencia?.

A nuestro juicio, son las mismas exigencias del principio de transparencia y probidad administrativa las que motivan la incorporación de procesos de precalificación y la creación de registros públicos, con el objetivo preciso que la concursabilidad en la licitación sea sobre ofertas presentadas por licitantes serios, que ofrezcan suficiente garantía para el interés general, tanto en los aspectos técnicos como financieros. En efecto, del principio de libre concurrencia no se puede llegar a concluir que el Estado contrate con quien no tiene capacidad para obligarse, o no ofrece garantías para un honesto cumplimiento de lo pactado ${ }^{26}$.

Estimamos, que en el caso de las licitaciones restringidas, si bien las reglas de admisión de los oferentes son más restringidas, ello no involucra que no les sean aplicables las demás normas y principios propios de las licitaciones públicas, como la concursabilidad que debe existir entre los oferentes y que le permitan al Estado seleccionar la oferta más conveniente, tanto técnica como económica.

\section{Procedimiento de selección del oferente: licitación privada y tratado directo}

Una vez aclarado que la licitación pública es el procedimiento administrativo general utilizado por la Administración del Estado para seleccionar la oferta

\footnotetext{
General de Contratistas del Ministerio de Obras Públicas, o Registro de Contratistas, será común y único para las Direcciones Generales, Direcciones y Servicios dependientes del Ministerio de Obras Públicas e Instituciones que se relacionen con el Estado por su intermedio, dependerá de la Dirección General de Obras Públicas y será de conocimiento público. El Registro de Contratistas estará formado por el Registro de Obras Mayores y el Registro de Obras Menores.

26 Sayagués 2005, 118.
} 
más conveniente, es preciso aclarar que en forma excepcional la Administración del Estado podrá optar por mecanismos de contratación distintos de la licitación pública, como la licitación privada o el trato directo, cuando el cambio de procedimiento de selección sea debidamente fundado, o en los casos que la naturaleza de la negociación haga procedente una contratación directa.

Lo anterior obedece a que los motivos o circunstancias que justifican la utilización de la licitación pública como el procedimiento administrativo general, se relativizan cuando la satisfacción de la necesidad pública exige mayor grado de inmediatez que no comulga con el lento transitar de la licitación pública, como en los casos de urgencia, o que la experiencia, profesionalismos o los conocimientos técnicos que ostenta un determinado oferente respecto de una determinada industria, y que obligan a la Administración del Estado a flexibilizar los procesos de selección hacia los potenciales oferentes, sin sacrificar la concursabilidad ni la finalidad de obtener la mejor oferta ${ }^{27} \mathrm{O}$ simplemente acudir a la negociación directa cuando sea imposible la concursabilidad, sin un desmedro de la satisfacción inmediata de las necesidades públicas.

Las excepciones a la licitación pública generalmente se fundan en cuestiones de imposibilidad legal, de naturaleza o de hecho o por motivos de conveniencia administrativa, seguridad pública o incluso relacionada con el presupuesto oficial del contrato público. Si bien, no existe una regla general sobre qué se entiende por licitación privada o trato directo, de las normas que regulan los contratos administrativos típicos, podemos extraer reglas sobre su procedencia, sus condiciones esenciales, limitaciones y relaciones respecto del procedimiento de licitación pública.

Excepcionalmente el Estado podrá elegir libremente a su contratista sin concurrencia, puja, ni oposición de oferentes, sin necesidad de regular previamente un concurso ni preparar bases de licitación. Ello, no obstante que se trata de un procedimiento negociado, en que por la naturaleza del futuro contrato no es posible acudir a la licitación pública ni a la licitación privada, tales casos son, por ejemplo, emergencias en las cuales la autoridad simplemente emite una orden de trabajo y el contratista la acepta, dándose por perfeccionado el contrato ${ }^{28}$.

Cabe señalar que también constituye una excepción a la licitación pública la existencia de convenios marcos, por cuanto permite que la Administración pueda celebrar contratos de suministrados o de prestación de servicio a través de un catálogo electrónico previamente determinado por la Dirección de Compras y Contratación Pública. De esta forma, la instauración de convenios marcos tiene por objetivo lograr un ahorro de recursos para el Estado, que se materializa una vez que se ponen a disposición de las entidades compradoras un conjunto de bienes y servicios, previamente licitados y

\footnotetext{
27 Comadira 2000, 106.
}

28 Moraga 2019, 323. 
seleccionados, con condiciones superiores a la que ofrece el mercado, salvo la existencia de condiciones mas ventajosas de contratación ${ }^{29}$.

\subsection{Licitación privada}

Dromi entiende que la licitación privada es el procedimiento de contratación en el que intervienen como oferentes solo las personas o entidades expresamente invitadas por el Estado, por cuanto se trata de una invitación o pedido de ofertas dirigida a empresas o personas determinadas discrecionalmente para cada caso ${ }^{30}$.

En este sentido, la Administración busca seleccionar a las personas que le parecen más idóneas para realizar la prestación que le interesa y a ellos dirige su proposición ${ }^{31}$. Constituye un llamado que el órgano administrativo hace a un conjunto predeterminado de oferentes $y$, teniendo una lista de interesados, la Administración efectúa el concurso respectivo entre ellos ${ }^{32}$.

Normativamente, el artículo 7 letra b) señala que para los efectos de la Ley $N^{\circ}$ 19.886, de 2003, se entiende por licitación privada o propuesta privada, el procedimiento administrativo de carácter concursal, previa resolución fundada que lo disponga, mediante el cual la Administración invita a determinadas personas para que, sujetándose a las bases fijadas, formulen propuestas de entre las cuales seleccionará y aceptará la más conveniente. Por su parte, el artículo 45 del DS N²50, 2004, dispone que para proceder a la licitación privada debe existir una resolución fundada, y un mínimo de tres posibles proveedores interesados que tengan negocios de naturaleza similar a los que son objeto de la licitación privada. Por su parte, el artículo 47 señala que en cuanto a la elección de los oferentes, la entidad licitante deberá invitar a proveedores respecto de los cuales tenga una cierta expectativa de recibir respuestas a las invitaciones efectuadas, prefiriendo a aquéllos que se encuentren inscritos en el Registro de Proveedores.

En un sentido similar, el artículo $3 N^{\circ} 27$ del DS N 75, de 2004, también acude al criterio numérico para configurar la procedencia de la licitación privada, señalando que la propuesta privada es la oferta efectuada por un proponente a petición del Ministerio, solicitada por escrito a tres o más contratistas de la especialidad. No obstante, el artículo $1^{\circ}$ del DS N²75, de 2004, se remite al artículo 86 del DFL N 850, ley orgánica del Ministerio de Obras Públicas, que regula como causales que habilitan la licitación privada la existencia de emergencias, contratos administrativos terminados parcialmente, entre otras.

De esta manera, siguiendo la jurisprudencia de la Contraloría General de la República la sola invitación a presentar ofertas o cotizaciones no queda

29 Barra y Celis 2009, 44 y 45.

30 Dromi 2010, 114.

31 Cordero 2015, 429.

32 Bermúdez 2011, 212. 
comprendida dentro del concepto de licitación privada, pues esta última se caracteriza por consistir en un concurso previamente regulado en un cuerpo normativo que constituye lo que se denomina bases administrativas, característica que no concurre tratándose de las cotizaciones directas ${ }^{33}$.

Por lo tanto, de conformidad con el artículo 48 del DS N²50, de 2004, a la licitación privada le son aplicables -en todos aquellos que sea procedente- las normas de la licitación pública. En efecto, le son aplicable a la licitación privada -en forma matizada- los principios de igualdad y estricta sujeción a las bases y el principio de probidad y transparencia, porque a la postre la licitación privada ostenta la naturaleza de procedimiento administrativo de naturaleza concursal ${ }^{34}$.

\subsection{Causales de trato directo}

De conformidad con el artículo 7 letra c), el trato directo o contratación directa es el procedimiento de contratación que, por la naturaleza de la negociación que conlleva, debe efectuarse sin la concurrencia de los requisitos señalados para la licitación o para la privada. Por su parte, el artículo $4 \mathrm{~N}^{\circ} 28$ del DS $N^{\circ} 75$, señala que el trato directo es la forma de contratar la realización de una obra sin llamar a licitación, conviniéndose con un contratista inscrito en el registro respectivo, los precios, plazos y normas que regirán el contrato.

Como se puede apreciar, el legislador ha elaborado un concepto de trato directo por exclusión al utilizar la frase "sin la concurrencia de los requisitos señalados para la licitación o propuesta pública y para la privada", es decir, trato directo sería todo aquel procedimiento de contratación que no es licitación pública o privada. Por lo tanto, el legislador no analiza el elemento esencial del trato directo, que es la ausencia de concursabilidad, por cuanto el trato directo es cerrado, sin puja ni claridad de la oferta más conveniente entre los distintos proyectos.

En este sentido, la doctrina hace hincapié en que el trato directo "El Estado elige directamente el cocontratante sin concurrencia u oposición, de la misma manera que los particulares, y celebra el convenio" 35.

De un análisis somero de los artículos 9 de la Ley $\mathrm{N}^{\circ} 18.575$, del artículo 7 letra c) de la Ley $N^{\circ} 19.886$, de los artículos 10 y 49 del DS N²50, de 2004, y el DS $N^{\circ} 75$, de 2004, se desprende que el trato directo es una forma de contratación administrativa excepcional al sistema de propuesta pública y

\footnotetext{
33 Dictamen $N^{\circ} 46.532$ (2000). En efecto, la concursabilidad es una regla clara que favorece la transparencia, que es exigible por el Estado, no solo en la licitación de contratos públicos, sino también de autorizaciones que le confieran a un titular un derecho exclusivo y excluyente, como por ejemplo el artículo 3 de la Ley N 19.995 de Casinos de Juegos, que obliga a licitar la concesiones de casinos, o el artículo 13 de la Ley $N^{\circ}$ 18.168, General de Telecomunicaciones, o finalmente, los artículos 135 y siguientes de la Ley $N^{\circ} 20.805$ sobre licitación del suministro eléctrico respecto de las empresas de distribución eléctrica.

34 ACEVEDo 2018, 32.

35 Dromı 2010, 114.
} 
propuesta privada, siendo procedente su aplicación solo en aquellos casos en que así lo dicta la propia naturaleza de la operación que se trata de realizar ${ }^{36}$.

En este sentido, la Contraloría ha señalado que "(...) la contratación directa es un mecanismo de carácter excepcional, por lo que su aplicación solo corresponde en los casos específicos que ordenamiento jurídico prevé y que requieren una demostración efectiva y documentada de los motivos que justifican su procedencia, debiendo acreditarse de manera suficiente la concurrencia simultánea de todos los elementos que configuran las hipótesis contempladas en la normativa cuya aplicación se pretende" ${ }^{\prime 3}$.

De este modo, el trato directo no ostenta la naturaleza de procedimiento administrativo de carácter concursal, por cuanto no existe oposición entre oferentes de los cuales la Administración pueda seleccionar la oferta más conveniente. Por lo tanto, la naturaleza excepcional del trato directo obliga a los órganos del Estado a evaluar fundadamente las causales reguladas por el legislador, que le permitan omitir la concursabilidad propia de las licitaciones públicas y privadas ${ }^{38}$.

De esta forma, para sustentar el trato directo por cualquier causal, no basta la sola referencia a las disposiciones legales y reglamentarias que lo fundamenten, ni la buena impresión que se haya formado el servicio contratante respecto de la empresa favorecida, ni la circunstancia de haberse suscrito anteriormente otros convenios similares con ese mismo proveedor ${ }^{39}$, lo cual implica que "en razón de su carácter excepcional, la causal de trato directo empleada, requiere que, al momento de invocarla, se acrediten efectiva y documentadamente las razones que justifican su procedencia", en consecuencia, debe acreditarse de manera suficiente la concurrencia simultánea de todos los elementos que configuran las hipótesis contempladas en la normativa cuya aplicación se pretende ${ }^{40}$.

En efecto, la falta de justificación suficiente de una causal de trato directo implica un incumplimiento del deber de los órganos de la Administración del Estado de realizar sus contrataciones preferentemente a través de procedimientos de licitación pública y asimismo contraviene el principio de libre concurrencia que debe imperar en la propuesta pública, de conformidad con lo dispuesto en el artículo $9^{\circ}$ de la Ley N 18.575, Orgánica Constitucional de Bases Generales de la Administración del Estado ${ }^{41}$ y, finalmente, es una infracción grave al principio de motivación de los actos administrativos exigido por los artículo 11 y 41 de la Ley N 19.880, de 2003, como se ve más adelante.

36 Dictamen No 61.442 (2012); Dictamen Nº 71.748 (2012).

37 Dictamen No 10.172 (2017); Dictamen No 8.805 (2016).

38 Dictamen $N^{\circ} 46.532$ (2000).

39 Dictamen $N^{\circ} 26.006$ (2016).

40 Dictamen $N^{\circ} 8.805$ (2016).

41 Dictamen $N^{\circ} 68.458$ (2012). 


\section{Análisis crítico de las excepciones a la licitación pública}

Hemos señalado que la licitación pública es la regla general, no obstante por razones jurídicas, mérito, oportunidad o conveniencia, la autoridad administrativa podrá omitir la licitación pública, optando entre la licitación privada o el tratado directo. Sin embargo, conviene aclarar que al regular las causales que le permitan a la Administración del Estado invocar la licitación privada o el trato directo, el legislador no distingue aquellas propias de la licitación privada, de las aplicables al trato directo, sino que podemos afirmar que es la naturaleza del futuro contrato la que define el procedimiento de selección del contratista.

Normativamente, el artículo 9 de la Ley N 18.575, Orgánica Constitucional de Bases Generales de la Administración del Estado, para la procedencia de la licitación privada exige una resolución fundada y, para el trato directo, lo deja entregado a un concepto jurídico abierto e indeterminado -la naturaleza de la negociación- que la autoridad administrativa licitante deberá apreciar en el caso concreto, a fin de sortear la burocracia propia de la licitación pública.

Tradicionalmente, respecto del trato directo las hipótesis incluidas en la naturaleza de la negociación se encuentran asociadas a situaciones de urgencia o la existencia de un proveedor único para la satisfacción de la necesidad pública respectiva ${ }^{42}$. No obstante, como veremos a estas hipótesis de trato directo, han sido complementadas o incluso abultadas, por el legislador o la Administración en desmedro de la licitación pública.

\subsection{Licitaciones públicas sin interesados}

De conformidad con el artículo 8 letra a) de la Ley $N^{\circ} 19.886$, de 2003, y el artículo $10 \mathrm{~N}^{\circ} 1$, del DS $\mathrm{N}^{\circ} 250$, de 2004, procederá el trato directo, cuando en las licitaciones públicas no se hubieren presentado interesados, esto es, cuando la licitación pública ha sido declarada desierta por ausencia de interesado o haberse presentado ofertas inadmisibles. La misma idea se encuentra recogida en la letra a) del artículo 86 del DFL N 850, del Ministerio de Obras Públicas, que habilita la adjudicación por cotización privada si a la propuesta pública respectiva no se hubieren presentado interesados, en cuyo caso las bases de licitación servirán para la asignación por propuesta privada.

Ahora bien, a nuestro juicio la alteración del procedimiento de contratación no es automática, por cuanto la autoridad administrativa no podría declarar desierta la licitación pública e inmediatamente acudir a la licitación privada o al trato directo, por cuanto la ley en forma general (artículo 9 de la Ley $\left.N^{\circ} 18.575\right)$ y las leyes especiales y sus respectivos reglamentos, establecen un orden de prelación respecto de los procedimientos de selección del contratista. En efecto, ante una licitación pública declarada desierta solo

42 Dictamen N 45.278 (2000); Dictamen, Nº 34.434 (2000). 
permite acudir a la propuesta privada y, en último término al trato directo, si la causa de dicha declaración ha sido la ausencia de interesados.

Por lo tanto, si la licitación se declaró desierta debido a otros motivos, tales como la falta de conveniencia económica o técnica de las ofertas presentadas no sería posible, según la redacción de la letra a) del artículo 8 de la Ley 19.886, acudir a la contratación directa, pues dicho precepto solo hace referencia a la falta de interesados. En caso contrario, bastaría que la Administración declarara inconveniente las ofertas presentadas por los interesados para acudir a la licitación privada o al trato directo, aumentando el grado de discrecionalidad de la Administración del Estado ${ }^{43}$.

En este sentido, incluso se podría considerar que no basta un solo llamado, en el contexto de la licitación pública, para pretender declararla desierta, por cuanto lo relevante es la mayor concursabilidad de los bienes públicos. Así, para evitar abusos en el ejercicio de esta atribución por parte de la Administración, debe considerarse la acreditación fehaciente de la falta de interés de los licitantes, reflejada en que ninguno hubiese presentado oferta formal, lo cual es coherente con el mandato realizado por el legislador, en cuanto a que las bases que se fijaron para la licitación pública deberán ser las mismas que se utilicen para contratar directamente o adjudicar en licitación privada.

\subsection{Contratos resueltos o terminados anticipadamente}

Según el artículo 8 letra b) de la Ley $N^{\circ} 19.886$, y el artículo $10 N^{\circ} 2$, de su Reglamento, la autoridad administrativa podrá acudir a licitación pública o al trato directo, cuando la nueva contratación se encuentra relacionada con la realización o terminación de un contrato que haya debido resolverse o terminarse anticipadamente por falta de cumplimiento del contratante u otras causales y cuyo remanente no supere las 1.000 unidades tributarias mensuales. Por su parte, la letra b) del artículo 86 del DFL $N^{\circ} 850$, hace referencia a la resolución anticipada de contratos por incumplimientos del contratista o por otras causales.

No obstante lo evidente de esta causal, es conveniente hacer algunas prevenciones, a fin de evitar que la Administración se sienta tentada a terminar unilateralmente un contrato administrativo. En primer lugar, la terminación unilateral ostenta la naturaleza jurídica de una potestad que permite que la Administración pueda declarar unilateralmente la rescisión del contrato, sin

\footnotetext{
43 La doctrina agrega las siguientes prácticas reñidas con la ausencia de motivación de la causal de falta de interesados en la licitación, entre ellas: (i) declarar desierta la licitación, porque en el entender del licitante las bases adolecerían de algún vicio que las hace invalidas, no existiendo reclamo de ningún licitantes; (ii) declarar desierta la licitación debido a una impugnación del procedimiento contractual administrativo, sin que se encuentre afinada la impugnación; (iii) declarar desierta la licitación antes que la Administración deje el procedimiento en estado de abrir sesión fijada para recibir las ofertas. Cfr., Moraga 2019, 331.
} 
necesidad de estipulación contractual de las partes, y sin necesidad de acudir a los tribunales de justicia ${ }^{44}$.

En segundo lugar, en los contratos administrativos nominados la terminación unilateral del contrato se encuentra asociada a incumplimientos graves de las obligaciones contraídas por el contratante. En este sentido, en el caso del contrato de suministro y prestación de servicios el artículo 13 de la Ley $N^{\circ} 19.886$, que los contratos administrativos regulados en dicha ley podrán modificarse o terminarse anticipadamente por el incumplimiento grave de las obligaciones contraídas por el contratante. Por su parte, el DS No 250, de 2004, del Ministerio de Hacienda, reitera que la Administración contratante puede dar por terminado en forma anticipada el contrato de suministro o de prestación de servicio ante incumplimientos graves de las obligaciones contraídas por el contratante, remitiéndose a las bases de licitación para que establezcan la indemnización o compensación. Adicionalmente, el artículo 79 del mismo reglamento establece que la resolución o decreto que ponga término anticipado al contrato definitivo debe ser fundado ${ }^{45}$.

En el caso del contrato de obra pública, específicamente en el artículo 151 se señala que la Dirección General de Obras Públicas podrá poner término administrativamente y en forma anticipada a uno o más contratos en los casos que el contratista: (i) cayere en quiebra; (ii) si el contratista no acatare las órdenes o instrucciones impartidas por la Dirección; (iii) si el contratista no diere cumplimiento al programa oficial de trabajo; o (iv) si por un error en la ejecución de los trabajos la obra quedara con defectos graves que no pudieran ser reparados y ellos comprometieran su seguridad u obligaran a modificaciones sustanciales del proyecto.

A su vez, el mismo cuerpo normativo regula en el artículo 148 una especie de revocación por cambio de circunstancias, señalando que el Ministerio de Obras Públicas tiene derecho a poner término anticipadamente a un contrato, o a ordenar la paralización de la obra, cuando no haya fondos disponibles para llevarla adelante, o cuando así lo aconsejen sus necesidades ${ }^{46}$.

Finalmente, el DS No 900, de 1996, regula en el artículo 27 que la concesión se extingue por el incumplimiento grave de las obligaciones de concesionario, que de conformidad con el artículo 23, dicen relación con la conservación de la obra y la prestación de los servicios en condiciones de normalidad, continuidad, suprimiendo las causas que originen molestias, in-

\footnotetext{
44 Comadira 2000, 134.

45 Por otra parte, el mismo artículo 13 de la Ley $N^{0} 19.886$, establece en la letra e) que el órgano contratante puede regular mediante bases administrativas causales adicionales de extinción de los contratos administrativos de suministro o de prestación de servicio. En este sentido, el artículo 18 del Reglamento de la Ley $N^{\circ} 19.886$ establece, que en las bases de licitación para Convenios Marcos, la Dirección de Compras y Contratación Pública debe contemplar como una causal para poner término anticipado a dichos convenios, el hecho que el contratista incumpla sus obligaciones para con la entidad requirente.

46 OelCKers 1985, 235.
} 
comodidades, inconvenientes o peligros para los usuarios de las obras. Por su parte, el artículo 28 ter), señala que si el interés público así lo exigiere, el Presidente de la República, previo informe del Consejo de Concesiones y mediante decreto fundado del Ministerio de Obras Públicas, que deberá llevar la firma del Ministro de Hacienda, podrá poner término anticipado a la concesión cuando un cambio de circunstancias hiciere innecesaria la obra o servicio para la satisfacción de las necesidades públicas, o demandare su rediseño o complementación de tal modo que las inversiones adicionales necesarias para adecuar la obra a las nuevas condiciones superen el veinticinco por ciento del presupuesto oficial de la obra.

Por su parte, es preciso remitirse a lo establecido en el DS N $N^{\circ} 956$ de 1999, recientemente modificado por el DS N²15, de 26 de abril de 2010, ambos del Ministerio de Obras Públicas que establece el Reglamento de la Ley de Concesiones, el cual señala que son las bases de licitación las que deben establecer las causales por las cuales el Ministerio de Obras Públicas puede solicitar la declaración de incumplimiento grave de las obligaciones del contrato de concesión, debiendo activar el procedimiento de nombramiento de un interventor para evitar la interrupción en la prestación regular y continua del servicio público concesionado ${ }^{47}$.

Por lo tanto, la causal debe ser interpretada como una potestad conferida por ley, evitando que la Administración invoque causas de extinción contractual, creadas en forma administrativa al alero de las bases de licitación, e incluso que desconozcan causales previamente reguladas por la misma Administración. Este planteamiento ha sido reconocido por la jurisprudencia ${ }^{48}$ que a propósito de un contrato de comodato precario suscrito entre el Servicio Metropolitano de Vivienda y Urbanización (Serviu) y una entidad privada, ambas partes optaron por tasar los supuestos de extinción del contrato, restringiendo la potestad de terminar en forma unilateral y administrativa el contrato. Sin embargo, el Serviu, en contra de sus actos propios procedió a dar por terminado el contrato en forma unilateral y administrativa. Al respecto, la Corte Suprema señaló que:

"(...) la única forma de que la referida cláusula sea válida y produzca efectos, en atención a que, como se dijo, el contrato de comodato tiene

\footnotetext{
47 Cabe señalar, que entre las causales que dan lugar a la extinción del contrato de concesión - la caducidad del mismo, las Bases de Licitación consideran generalmente, entre otras, las siguientes: (i) La disminución del capital de la sociedad concesionaria sin autorización expresa del Ministerio de Obras Públicas; (ii) El no cumplimiento reiterado de los estándares mínimos de servicio establecidos en el contrato de concesión; (iii) Cobrar tarifas superiores a las establecidas en el contrato de concesión a los usuarios. Una vez acreditado el incumplimiento grave de las obligaciones impuestas por el contrato al concesionario, lo cual le corresponde determinar a la Comisión Arbitral -órgano jurisdiccional especial regulado por el legislador para cada contrato individualmente considerado- el Ministerio de Obras Públicas puede nombrar a un funcionario -en calidad de interventor- con la finalidad de darle continuidad al contrato, y por ende, evitar la interrupción en la prestación del servicio público.

48 Serviu Metropolitano con Instituto de Educacion Rural (2017).
} 
plazo definido que impide establecer una condición meramente potestativa sujeta a la sola voluntad del acreedor, pasa por reconocer que el término al contrato en un tiempo menor al que fue pactado, solo es procedente si se vincula a la existencia de una necesidad urgente para el Serviu Metropolitano, cuestión que en todo caso siempre estará ligada a la obligación de indemnizar los perjuicios que tal decisión causare al comodatario".

Concluyendo que, "(...) la interpretación restrictiva que se debe entregar a la referida cláusula, impide que se pueda reconocer que la necesidad de un servicio distinto al Serviu permita poner término anticipado al contrato, por lo que el requerimiento destinado a dotar de un inmueble al Consejo Nacional de Desarrollo Urbano, entidad que si bien pertenece a la Administración, es un organismo que no forma parte del Serviu, no puede dar pábulo para aplicar la facultad contemplada en la mencionada cláusula sexta, sin que aquello cambie por la circunstancia de estar ambos servicios bajo la dependencia del Ministerio de Vivienda y Urbanismo, pues igualmente en estas condiciones no se configura la "necesidad" del Serviu".

\subsection{Emergencia, urgencia o imprevistos}

De conformidad con el artículo 8 de la ley 19.886, y el artículo $10 \mathrm{~N}^{\circ} 3$ del DS N 250 , de 2004, procederá la licitación privada o contratación directa en casos de emergencia, urgencia o imprevisto, calificados mediante resolución fundada del jefe superior de la entidad contratante, bajo sanción de multa en contra del jefe superior del servicio cuando la causal de contratación directa no sea correctamente invocada. Una norma similar encontramos en el artículo 86, letra c) del DFL N 850, de 1998, que establece la ley orgánica del Ministerio de Obras Públicas, en la cual se exige que la invocación de la causal de cotización privada se encuentre contenida en un decreto supremo.

Claramente, la calificación de la emergencia, urgencia o imprevisto es una cuestión de hecho que corresponde ser calificada a la Administración activa, gozando de un amplio campo para apreciar la situación fáctica que le permite eximirse del procedimiento administrativo general de licitación pública ${ }^{49}$. Sin embargo, la urgencia requiere necesariamente de circunstancias objetivamente verificables como, por ejemplo, mediante estudios técnicos previos que sirvan de suficiente motivación a la decisión administrativa. Así, por ejemplo, cuando la autoridad acude al trato directo por razones de urgencia, invoca la causal motivadamente y dispone parámetros que los contratantes suscriban el futuro contrato ${ }^{50}$.

\footnotetext{
${ }_{49}$ El artículo 111 del DFL N 850, de 1998, que contempla la Ley Orgánica del Ministerio de Obras Públicas, dispone que en caso de emergencia los actos administrativos pueden ser cumplidos de inmediato, prescindiendo en forma anticipada del trámite de toma de razón, debiendo de conformidad con el artículo 10 de la Ley $N^{0} 10.336$ remitirse para su tramitación por la Contraloría General de la República dentro del plazo de 30 días, contados desde que se haya dispuesto la medida.

50 Nutriplus Alimentación y Tecnología S.A. con Junta Nacional de Auxilio Escolar y Becas (2019).
} 
Dromi aclara que no toda urgencia habilita la excepción procedimental, sino que la urgencia debe ser actual, concreta, manifiesta e impostergable y de una naturaleza tal que la necesidad que origine no pueda ser satisfecha en tiempo oportuno más que por el procedimiento de excepción autorizado. En caso contrario, se correría el riesgo de considerar como cierta una situación de urgencia irreal, generalizándose una excepción que debe ser interpretada en términos restrictivos y limitados ${ }^{51}$.

Conviene aclarar que la emergencia y urgencia no son íntegramente sinónimas de una situación imprevista que justifique invocar la contratación directa, ello por cuanto la situación imprevista no puede ser fruto de la negligencia o incumplimiento de deberes que induzcan a la Administración a calificar como imprevisible una materia que es fruto del incumplimiento de sus obligaciones, sino bastaría con que los órganos públicos dejasen de cumplir con sus obligaciones para variar los procedimientos de contratación y sortear la licitación pública ${ }^{52}$.

\subsection{Existencia de un único proveedor del bien o servicio}

De conformidad con el artículo 8 letra d) de la Ley $N^{\circ} 19.886$, y el artículo 10 $N^{\circ} 4$, del DS N²50, de 2004, la Administración puede optar por la licitación privada o el trato directo en el caso que exista un único proveedor de un bien o servicio. Cabe señalar, que esta causal puede ser perfectamente subsumida en la letra g) del artículo $8^{\circ}$ de la Ley, por cuanto es un caso que la naturaleza de la negociación obliga a prescindir de la licitación pública, así lo ha señaló la Contraloría en su oportunidad, que:

"la naturaleza de la negociación determina la correspondencia del trato directo en aquellas situaciones en que las circunstancias o características del contrato que se trata de celebrar hacen innecesario llevar a cabo un proceso de propuesta como el caso en que se debe adquirir un producto y solo existe un único proveedor del mismo" ${ }^{13}$.

Sin embargo, por simple que pueda parecer la comprobación de un solo proveedor de un bien o servicio, la misma Contraloría ha ido exigiendo un alto nivel de motivación en la invocación de esta causal, a fin de evitar contrataciones administrativas dirigidas que excluya a potenciales contratistas que ofrezcan un producto alternativo de la misma calidad. En efecto, la Contraloría ha sido estricta en analizar la motivación del acto administrativo, prohibiendo que el acto administrativo se limita a consignar que existe solo un proveedor

\footnotetext{
51 Dromi 2010, 141.

52 Dictamen N 52.018 (2007). En este sentido, la Contraloría ha señalado que "(...) no es posible entender que la causal invocada en la especie se encuentre fundamentada en la ocurrencia de un imprevisto, ya que la duración del convenio, era un hecho conocido por ese Ministerio, toda vez que la cláusula quinta de ese contrato disponía que su vigencia se extendería por 48 meses a contar de la fecha consignada en el certificado de recepción final del sistema BIP". Vid., Dictamen $N^{\circ} 87.444$ (2015).

53 Dictamen $N^{\circ} 45.278$ (2000).
} 
en condiciones de ofrecer el servicio requerido, sin fundamentar esta circunstancia ni acompañar antecedente alguno en tal sentido, que sirva para acreditar que la empresa invitada tenga el carácter de proveedor único ${ }^{54}$.

\subsection{Por la naturaleza de la negociación}

Como hemos señalado, esta causal se encontraba regulada en el artículo 8 bis de la Ley $N^{\circ} 18.575$, con anterioridad a la dictación de la Ley $N^{\circ} 19.886$ y su reglamento, y ha sido la que ha permitido a la Administración invocar en términos amplios el trato directo. Normativamente, el artículo 8 letra g) de la Ley $N^{\circ} 19.886$, exige la presencia de circunstancias o que las características del contrato hagan del todo indispensable acudir al trato directo, remitiendo al reglamento la fijación de criterios moduladores de las circunstancias o características de la contratación directa. Esta norma no se encuentra presente en los demás contratos administrativos, esto es, obra pública y concesión de obra pública, por cuanto la existencia de un sistema de registro públicos, asociados a la experiencia en infraestructura excluye la posibilidad de acudir a criterios de selección amplios e imprecisos.

En efecto, el artículo $10 N^{\circ} 7$ del reglamento fija los criterios que especifican o complementan las circunstancias o características del contrato, que permiten acudir a la contratación directa por la naturaleza de la negociación. Cabe señalar, en forma anticipada que los criterios no son uniformes y constituyen a nuestro juicio una cláusula amplia que puede permitir sortear la licitación pública, por ello los agruparemos en tres tipos de criterios.

\section{a. Contrataciones inferiores a 1.000 UTM o contrataciones menores}

Entre los criterios fijados por el reglamento que se consideran dentro de la naturaleza de la negociación, se encuentran aquellos contratos cuya cuantía no excede de 1.000 UTM, sea que provengan de la prórroga de un contrato de suministro o de prestación de servicio indispensable para las necesidades del ente público, como en el caso de la letra a) del artículo $10 N^{\circ}$ 7; o cuando el costo de evaluación de las ofertas, desde el punto de vista financiero o de utilización de recursos humanos, resulta desproporcionado en relación al monto de la contratación y ésta no supera las 100 UTM (artículo $10 N^{\circ} 7$ letra j); o cuando se trate de la contratación de servicios personales especializados cuyo monto sea inferior a 1.000 UTM (artículo $10 \mathrm{~N}^{\circ} 7$ letra m); y, finalmente, cuando se trate de adquisiciones inferiores a 10 UTM (artículo $10 \mathrm{~N}^{\circ} 7$ letra n).

En todos estos casos, a nuestro juicio resulta adecuado prescindir de la licitación pública, por cuanto las cuantías involucradas atentarían contra los principios de eficiencia y eficacia y contra las exigencias de celeridad de la actividad administrativa. Sin embargo, la postergación de la licitación pública, no es una renuncia absoluta a los principios de transparencia y concursabilidad ni al potencial control de la Contraloría General de la República. Lo

54 Dictamen No 23.348 (2000). Dictamen Nº 50.123 (2011). 
anterior, era seguido por el actualmente derogado artículo $10 \mathrm{~N}^{\circ}$ 8, del Reglamento, que habilitaba a la entidad licitante a que proceder a la licitación pública, si así lo estimare ${ }^{55}$.

\section{b. Contrataciones asociadas a la confianza del servicio y del contratista}

Los criterios que entrega el reglamento para proceder al trato directo en las letras c), d), e), f), g), h) y k) del artículo $10 \mathrm{~N}^{\circ}$ 7, tiene como objeto sortear la licitación pública, en primer lugar por razones técnicas de los servicios requeridos por el órgano público, como un servicio que provenga del titular de la propiedad intelectual como, por ejemplo, la provisión de un determinado sistema computacional; o por razones asociadas a la reposición o complementación de equipos o servicios accesorios compatibles con sistemas o infraestructura previamente adquirida por el órgano público; o cuando la contratación consista en la compra de bienes o la contratación de servicios destinados a proyectos específicos de docencia o extensión en que la licitación pública afecte la eficacia del proyecto, como la contratación de un sistema de revista en una universidad pública. En segundo lugar, de conformidad con el artículo $10 \mathrm{~N}^{\circ} 7$ del reglamento, dentro de la naturaleza de la negociación se encuentran algunas causales, asociadas a la confianza, a la seguridad, a la especialidad, a la importancia y al riesgo que podría generar la licitación pública sobre la contratación de determinados bienes y servicios.

A nuestro entender, los criterios entregados por el reglamento son excesivamente amplios e imprecisos, dando pábulo para la extensión de un margen de discrecionalidad que puede atentar contra el principio de probidad administrativa. Por ejemplo, cuando el reglamento dispone que la licitación pública puede afectar "la seguridad e integridad personal de las autoridades", debiendo acudir a un proveedor probado en su discreción y confianza (letra c), o cuando para sortear la licitación pública se invoca "la consideración especial de las facultades del proveedor" (letra d), o cuando se acude a "la confianza y seguridad derivada de la experiencia del proveedor" (letra f) o, finalmente, "cuando el conocimiento público propio de la licitación pone en serios riesgos el objeto y el eficacia del contrato" (letra h), consideremos que en todos estos casos, se acude a conceptos amplios e imprecisos difíciles de fundamentar objetivamente, aumentado el margen de libertad de la Administración para excluir la concursabilidad que confiere la licitación pública.

Claramente, lo anterior no se condice con el artículo 86 del DFL N²85, ni con el DS $N^{\circ} 75$ o el DS $N^{\circ} 900$, que se inclinan por establecer supuestos específicos para proceder a la contratación vía licitación privada o mediante el trato directo, lo cual no excluye la posiblidad que el legislador pueda acudir a criterios numéricos para distinguir los escenarios de licitación pública,

\footnotetext{
55 Dicha norma fue derogada por el DS N 821, de 21 de enero de 2020, del Ministerio de Hacienda, que Modifica el Decreto Supremo N²50, de 2004, del Ministerio de Hacienda, que Aprueba el Reglamento de la Ley N 19.886, de Bases sobre Contratos Administrativos de Suministro y Prestación de Servicios.
} 
de aquellos en los cuales la Administración puede restringir la libre concurrencia en beneficio de la eficiencia y eficacia.

En efecto, una vez expuesto el análisis crítico de cada una de las causales que le permiten a la Administración del Estado prescindir de la licitación pública, consideramos que existen causales tradicionales, concretas y justificables que en la medida que existan los supuestos fácticos respectivamente fundados, la Administración puede invocar la licitación privada o el trato directo, estos son, las situaciones calificadas de urgencia, las licitaciones sin interesados acreditables, la extinción anticipada del contrato dependiendo del grado de avance del contrato, y la presencia de montos mínimos, que por razones de eficiencia, eficacia y celeridad habilitan -previo test de motivación suficiente- habilitan a prescindir de la licitación pública.

Por otra parte, existen causales que a nuestro juicio, merecen ser revisadas por el legislador y la autoridad administrativa, a fin de aumentar la concursabilidad y la transparencia, tales como aquella que se funda en la confianza que ostenta la Administración en el contratista y que, por la naturaleza de la contratación, permiten prescindir de la licitación pública. Consideramos, que esta causal mal interpretada y aplicada puede generar un atentado a la transparencia y la concursabilidad, y una eventual captura del contratista hacia la Administración, generando una situación similar a la renovación automática de contratos, en desmedro de otros potenciales contratista que pudiesen ofrecer al Estado ofertas más convenientes ${ }^{56}$.

A nuestro juicio, no es discrecional la elección del procedimiento de contratación, entre licitación pública, licitación privada y trato directo, sino que cualquiera sea el procedimiento que a la postre sirve para la celebración del contrato administrativo, la potestad de selección es reglada sujeta a causales precisas y determinadas, que en algunos casos el legislador incorpora elementos discrecionales que le confieren un grado de libertad a la Administración del Estado, más no es un llamado a la arbitrariedad ni a la desviada interpretación de las mismas. Por lo tanto, el Estado no podría usar esa libertad excepcional que le entregan la licitación privada o el trato directo -ponderación racional- para convertir dichos procedimientos en la regla general, y de esta forma negar la concursabilidad y la transparencia que ofrece la licitación pública, negando el carácter general de la misma.

\section{Cambio de procedimiento y motivación administrativa}

Hemos señalado que el uso de concepto amplios como la confianza, la seguridad, el riesgo o la integridad, a que acuden los órganos administrativos para prescindir de la licitación pública, no son un llamado a una discrecional

\footnotetext{
56 Dictamen N 81.434 (2015), "Asimismo, aparece que ese instrumento contempla una cláusula de renovación automática, la que ha permitido que aquel se haya prolongado desde el año 2009 hasta esta data, lo que no resulta procedente, pues pugna tanto con el sistema de concurso público establecido en la normativa apuntada (...)". Vid., Delfos Ltda., con SCL (2008).
} 
amplia sin controles, por cuanto los órganos administrativos deben determinar por medio de una resolución fundada, los procedimientos que permitan resguardar la eficiencia, transparencia, publicidad, igualdad y no discriminación arbitraria en esta clase de adquisiciones. A su vez, siempre que se contrate por trato o contratación directa se requerirá un mínimo de tres cotizaciones previas, salvo que concurran las causales de las letras c), d), f) y g) del artículo $10 \mathrm{~N}^{\circ} 7$ del Reglamento.

Lo anterior queda reflejado en dos tópicos relevantes. En primer lugar, la Contraloría exige motivación precisa de los órganos públicos al invocar el trato directo, puesto que,"(...) para sustentar el trato directo por cualquier causal, no basta la sola referencia a las disposiciones legales y reglamentarias que lo fundamenten, ni la buena impresión que se haya formado el servicio contratante respecto de la empresa favorecida, ni la circunstancia de haberse suscrito anteriormente otros convenios similares con ese mismo proveedor, lo cual implica que en razón de su carácter excepcional, la causal de trato directo empleada, requiere que, al momento de invocarla, se acrediten efectiva y documentadamente las razones que justifican su procedencia, además de deber acreditarse de manera suficiente la concurrencia simultánea de todos los elementos que configuran las hipótesis contempladas en la normativa cuya aplicación se pretende" 57 .

Por lo tanto, "La falta de justificación suficiente de una causal de trato directo implica un incumplimiento del deber de los órganos de la Administración del Estado (salvo la existencia de convenios marco, que, como señalamos, no obliga a los municipios) de realizar sus contrataciones preferentemente a través de procedimientos de licitación pública, y asimismo contraviene el principio de libre concurrencia que debe imperar en la propuesta pública, de conformidad con lo dispuesto en el artículo $9^{\circ}$ de la Ley No 18.575, Orgánica Constitucional de Bases Generales de la Administración del Estado. Concurridos los hechos que sirven de fundamento para la contratación mediante trato directo, corresponde a la respectiva autoridad administrativa ponderarlos y efectuar la contratación en la forma indicada" ${ }^{58}$.

$Y$, en segundo lugar, el mismo ente contralor ha emitido pautas precisas respecto de la observancia del principio de probidad por los órganos públicos al momento de contratar, lo cual, por cierto, los obliga a motivar suficientemente sus decisiones para prescindir de la licitación pública en favor de la licitación privada o el trato directo ${ }^{59}$. Así, podemos destacar algunas

\footnotetext{
57 Dictamen $N^{\circ} 8.805$ (2016).

58 Dictamen No 68.458 (2012).

59 A la motivación, en general, se le suelen reconocer tres atributos: uno es pedagógico, en tanto explica de un modo adecuado lo que justifica la adopción de una determinada decisión; el otro es que constituye el primer umbral de control de legalidad interno de la decisión, porque la autoridad debe explicar si se da el supuesto de hecho para la adopción de la decisión y como subsume la regla de competencia que lo autoriza a actuar, y el tercero, es defensivo, porque permite hacer posible al afectado ejercer su derecho a la impugnación, sea por la vía del recurso
} 
directrices, orientadas a evitar el fraccionamiento del monto de compras para sortear la licitación pública, la interpretación estricta de las causales de inhabilidad para contratar con el Estado, el agotamiento de la discrecionalidad durante la etapa de adjudicación ${ }^{60}$.

De esta forma, el cambio de procedimiento administrativo de contratación no es una habilitación hacia la más amplia discrecionalidad, sino que la potestad debe ser ejercida dentro de los márgenes de la ley siguiendo el principio de razonabilidad. Al respecto, Huepe señala que, (...) el ejercicio de la discrecionalidad será lícito y no corregible jurídicamente cuando se ejerza, en primer lugar, legalmente, esto es, dentro de los límites de la legalidad estricta, esto es, la legalidad o marco jurídico abstracto que le otorga la norma jurídica habilitante específica, pero también cuando se ejerza razonablemente, esto es, dentro de los límites de la razonabilidad, (legalidad en sentido lato o amplio) que le otorga la norma jurídica habilitante general"61.

En la misma línea, la Corte Suprema hace suyas estas reflexiones doctrinarias al afirmar que, "los órganos jurisdiccionales se encuentran facultados para realizar un control de los actos que tienen su origen en el ejercicio de facultades discrecionales, en tanto se debe verificar que exista norma que en forma expresa entregue a la Administración una amplia facultad para decidir y que los presupuestos de hecho que determinan el ejercicio de tal facultad existan, como asimismo que el fin que ha sido previsto por el ordenamiento jurídico al otorgar la facultad jurisdiccional, se cumpla"62.

Por lo tanto, la alteración de procedimientos de contratación exige que la Administración del Estado motive la causal de cambio de procedimiento, en términos suficientes. La exigencia de motivación de los actos administrativos es hoy un requisito esencial para su validez, por cuanto, no basta que en el acto consten los elementos fácticos y jurídicos, sino que se exige una fundamentación y/o explicación circunstanciada y racional que permita detectar el iter lógico que ha seguido la Administración para adoptar la decisión respectiva, con independencia si el acto es favorable o desfavorable.

Tanto la jurisprudencia de la Contraloría como la Corte Suprema están contestes en que los actos administrativos -como manifestaciones del ejercicio de potestades públicas- deben ser motivados por exigencia del principio de igualdad e interdicción de la arbitrariedad. Así, el ente contralor ha señalado que los actos administrativos deben expresar "normas legales y reglamentarias que le sirven de fundamento, consideraciones de hecho que hacen aplicable la medida adoptada (...)"63. Además, ha elevado la motivación a requisito esen-

administrativo (revisión plena de la decisión, incluido el mérito) o bien de la acción jurisdiccional (revisión plena de legalidad). Vid., CORDERO 2017, 237.

60 Dictamen $N^{\circ} 2453$ (2018).

61 Huepe 2018, 233.

62 Pey Tumanoff Roxana con Mario Fernández Baeza Vicepresidente de La República y Otro (2017).

63 Dictamen Nº 40.452 (2006). 
cial de un acto administrativo señalando que "(...) la falta de motivación, por cuanto dicho requisito esencial, en tanto constituye el fundamento de ese acto administrativo $y$, por ende, se encuentra íntimamente vinculada a la decisión adoptada, debe concurrir al momento de la dictación del mismo"64.

Por su parte, la Corte Suprema ha sido más enfática en exigir motivación de los actos administrativos, proscribiendo las actuaciones administrativas automáticas. De la jurisprudencia de la Corte Suprema, se pueden detectar algunos avances progresivos en la exigencia de motivación de los actos administrativos. En un primer estadio, la Corte Suprema ha exigido que la motivación de los actos administrativos requiere una "relación circunstanciada de los fundamentos de la decisión de manera de verificar su existencia y no argumentaciones generales"65. En segundo lugar, la Corte Suprema agregó que el tribunal, al momento de realizar el control de los motivos de un acto discrecional, también debe considerar la importancia del acto administrativo y su complejidad, concluyendo entonces que existirían distintos grados y exigencias de motivación, lo que dependerá fundamentalmente de la naturaleza del acto administrativo. En efecto, los actos administrativos más complejos y con plazos de vigencia más elevados deben ser dictados con un mayor estándar de motivación ${ }^{66}$.

De lo anterior, queda claro que la ausencia de un correcto razonamiento jurídico en la justificación de la causal de cambio del procedimiento de contratación constituye un ejercicio ajeno a la legalidad y la motivación que se exige de los actos administrativos por nuestro ordenamiento jurídico, por cuanto un adecuado ejercicio de motivación permite a los ciudadanos escrutar el cómo y el quién de las contrataciones del Estado.

Para ello, se requiere que la motivación sea íntegra, esto es, que el acto administrativo debe indicar y desarrollar todos y cada uno de los motivos de hecho y derecho que le sirven de sustento, y no se admiten indicaciones parciales ni fraccionamiento de motivos. A su vez, la motivación debe ser coherente, esto es, que el acto administrativo tenga lógica y coherencia jurídica, que resulten persuasivos. Los fundamentos expresados en el acto deben permitir reproducir un razonamiento comprensible y apreciable como razonable por un tercero observador ${ }^{67}$.

\section{Conclusiones}

De lo expuesto en este trabajo podemos concluir que:

1. Que, antes de la entrada en vigencia de la Ley $N^{\circ} 19.886$, de 2003, sobre Bases sobre Contratos Administrativos de Suministro y Prestación de

\footnotetext{
64 Dictamen N 56.391 (2008).

65 Herrera Jiménez Carlos con Comisión de Libertad Condicional (2014).

66 Fernando Dougnac Rodríguez, Diego Lillo G., Gabriela Burdiles P., Rodrigo Pérez A. con María Ignacia Benítez Pereira, Ministerio del Medio Ambiente (2015).

67 Poblete 2018, 208-213.
} 
Servicios, la doctrina nacional discutía si el artículo 8 bis de la Ley $N^{\circ} 18.575$, Orgánica Constitucional de Bases Generales de la Administración del Estado, permitía que la Administración del Estado pudiese elegir libremente el procedimiento de contratación más adecuado, sin que existiese un orden de prelación entre los distintos procedimientos de selección del contratista.

2. Que, con la entrada en vigencia de la Ley $N^{\circ} 19.886$, de 2003, el panorama fue aclarado, por cuanto la ley privilegió el uso de la licitación pública como mecanismo general de contratación, relegando la licitación privada a la existencia de una resolución fundada, y el trato directo a la naturaleza de la contratación, de conformidad con causales tasadas y específicas.

3. Que, la misma idea es reiterada por el DFL N850, del Ministerio de Obras Públicas, que contiene su ley orgánica y por los DS N²7, de 2004, sobre obra pública y el DS N 900, de 1996 sobre concesión de obra pública, ambos del mismo ministerio, en cuanto privilegian la licitación pública por sobre la licitación privada y el trato directo, al regular causales específicas y regladas.

4. Que, con la introducción de los convenios marcos previstos en la Ley $N^{\circ} 19.886$, y con la regulación amplia y conjunta de las causales de licitación privada y trato directo, se genera nuevamente la interrogante sobre cuál es el procedimiento general de contratación, por cuanto las causales de licitación privada y trato directo confieren un margen de apreciación que permitiría prescindir de la licitación pública.

5. Que, revisadas las causales que le permiten a la autoridad administrativa prescindir de la licitación pública, consideramos que existen causales tradicionales, concretas y justificables para que la Administración puede invocar la licitación privada o el trato directo en busca de una eficiente contratación, tales como las situaciones calificadas de urgencia, las licitaciones sin interesados acreditables, la extinción anticipada del contrato dependiendo del grado de avance del contrato, y la presencia de montos mínimos.

6. Que, existen causales que es necesario revisar por el legislador y la autoridad administrativa, a fin de aumentar la concursabilidad y la transparencia, tales como aquella que se funda en la confianza que ostenta la Administración en el contratista y que por la naturaleza de la contratación permiten prescindir de la licitación pública, en términos amplios.

7. Que, la elección del procedimiento de contratación es reglada sujeta a causales precisas y determinadas, que en algunos casos el legislador incorpora elementos discrecionales que le confieren un grado de libertad a la Administración del Estado, más no es un llamado a la arbitrariedad ni a la desviada interpretación de las mismas.

\section{Bibliografía Citada}

Abarca Muñoz, Katerina (2013). Los principios de no formalización y estricta sujeción a las bases en los procedimientos de contratación pública. En: BockSANG HoLA, Gabriel y LARA 
Arroyo, José Luis [Coords.], Procedimiento Administrativo y Contratación Pública. Santiago, Legalpublishing, pp. 291-332.

Acevedo Alvear, Natalia (2018). Licitación Pública. Regulación y concurrencia. Santiago, Editorial Hammurabi, 208 pp.

Aróstica Maldonado, Iván (2002). Cómo y con quién contrata la Administración. VVAA, La Contraloría General de la República y el Estado de Derecho. Conmemoración por su $75^{\circ}$ años de vida institucional, Contraloría General de la República, pp. 303-310.

ARÓStica MALDONAdo, Iván (2006). Licitación pública: concepto, principios y tramitación. Revista Actualidad Jurídica № 13, pp. 291-313.

Barra Gallardo, Nancy y Celis Danzinger, Gabriel (2009). Contratación Administrativa bajo la Ley de Compras, Santiago, Legalpublishing, $2^{\mathrm{a}}$ edición, $177 \mathrm{pp}$.

Bermúdez Soto, Jorge (2011). Derecho Administrativo General. Santiago, Abeledo Perrot, $2^{\text {a }}$ edición, 604 pp.

Boquera Oliver, José María (1963). La selección de contratista. Procedimiento de selección y contrato. Madrid, Instituto de Estudios Políticos, 185 pp.

CASSAGNe, Juan Carlos (1999). El contrato administrativo. Buenos Aires, Abeledo-Perrot, 324 pp.

Comadira, Julio (2000). Licitación Pública. Buenos Aires, Depalma, 210 pp.

Cordero Vega, Luis (2015). Lecciones de Derecho Administrativo. Santiago, Thomson Reuters, $786 \mathrm{pp}$.

CORDERO VEGA, Luis, (2017). La motivación del acto administrativo en la jurisprudencia de la Corte Suprema. Revista de Estudios Judiciales, Nº4, pp. 231-250.

Diez SASTRE, Silvia (2012). La tutela de los licitadores en la adjudicación de contratos públicos. Madrid, Marcial Pons, 335 pp.

Dromi, Roberto (2010). Licitación Pública. Buenos Aires, Editorial Ciudad Argentina, $4^{\mathrm{a}}$ edición, 710 pp.

Huepe Artigas, Fabian (2018). Discrecionalidad administrativa y razonabilidad. Santiago, Thomson Reuters, $525 \mathrm{pp}$.

Marienhoff, Miguel (1993). Tratado de Derecho Administrativo. Buenos Aires, Abeledo-Perrot, T II, $850 \mathrm{pp}$.

Moraga Klenner, Claudio (2019). Contratación administrativa. Santiago, Thomson Reuters, $2^{\mathrm{a}}$ edición, $613 \mathrm{pp}$.

Oelckers Camus, Osvaldo (1985). La extinción del contrato administrativo de obra pública. Revista de Derecho de la Pontificia Universidad Católica de Valparaíso, No 9, pp. 209-241.

PANTOJa BAUZA, Rolando (2001). La propuesta pública: ¿es obligación, en la ley chilena como modalidad general de contratación administrativa?. La semana jurídica, $N^{\circ} 44$, pp. 5-6.

Precht Pizarro, Jorge (2001). Propuesta Pública: Contraloría y Ley de Bases. La semana jurídica, $N^{\circ} 47$, pp. 5-6.

Poblete Ortuzar, Domingo (2017). Caso Rectora de la Universidad de Aysén: Controlando la Discrecionalidad Presidencial. Sentencias destacadas, Libertad y Desarrollo, pp. 195-225.

Santamaría Pastor, Juan Alfonso (2018). Principios de Derecho Administrativo General. Madrid, lustel, $5^{\text {a }}$ edición, Tomo II, $663 \mathrm{pp}$.

Sayagués Laso, Enrique (2005). La Licitación Pública. Montevideo, Editorial B de F, 211 pp.

\section{Normas citadas}

Ley N ${ }^{0}$ 18.575, establece Ley Orgánica Constitucional de Bases Generales de la Administración del Estado. Diario Oficial, 5 diciembre 1986.

Ley N ${ }^{\circ}$ 19.653, sobre probidad administrativa. Diario Oficial, 14 diciembre 1999.

Ley N ${ }^{\circ} 19.886$, establece Bases sobre Contratos Administrativos de Suministro y Prestación de Servicios. Diario Oficial, 30 julio 2003.

Ley №20.285, sobre acceso a la información pública. Diario Oficial, 20 agosto 2008. 
Ley N 9/2017, sobre Contratos del Sector Público. Boletín Oficial del Estado, 8 noviembre 2017.

Ley N ${ }^{\circ} 80$, sobre el Estatuto General de Contratación de la Administración Pública de Colombia. Diario Oficial, 28 octubre 1993.

Ley $N^{\circ}$ 20.410, que Modifica la Ley de Concesiones de Obra Pública. Diario Oficial, 20 enero 2010.

DS N $N^{\circ} 250$, de 24 de septiembre de 2004, del Ministerio de Hacienda, que aprueba el reglamento de la Ley No 19.886. Diario Oficial, 24 septiembre 2004.

DS N ${ }^{\circ} 821$, de 21 de enero de 2020, del Ministerio de Hacienda, que Modifica el Decreto Supremo $N^{\circ} 250$, de 2004, del Ministerio de Hacienda, que Aprueba el Reglamento de la Ley $N^{\circ} 19.886$, de Bases sobre Contratos Administrativos de Suministro y Prestación de Servicios. Diario Oficial, 21 de enero de 2020.

DS N 900, de 18 de diciembre de 1996, del Ministerio de Obras Públicas, que establece la Ley de Concesiones de Obra Pública. Diario Oficial, 18 diciembre 1996.

DS N ${ }^{\circ} 75$, de $1^{\circ}$ de diciembre de 2004, del Ministerio de Obras Públicas, que regula el Reglamento de Contrato de Obra Pública. Diario Oficial, 1 diciembre 2004.

DS N ${ }^{\circ} 956$ de 1999, modificado por el DS N²15, de 26 de abril de 2010, que contiene el Reglamento de la Ley de Concesiones de Obra Pública. Diario Oficial, 26 abril 2010.

\section{Jurisprudencia citada}

Herrera Jiménez Carlos con Comisión de Libertad Condicional (2014): Corte Suprema, 2 diciembre 2014.

Fernando Dougnac Rodríguez, Diego Lillo G., Gabriela Burdiles P., Rodrigo Pérez A. con María Ignacia Benítez Pereira, Ministerio del Medio Ambiente (2015): Corte Suprema, 30 septiembre de 2015.

Serviu Metropolitano con Instituto de Educación Rural (2017): Corte Suprema, 11 noviembre 2017.

Pey Tumanoff Roxana con Mario Fernández Baeza Vicepresidente de La República y Otro (2017): Corte Suprema, 19 junio 2017.

Delfos Ltda., con SCL (2008): Corte Suprema, 19 mayo 2008.

Constructora e Inmobiliaria Amulen SpA con Ministros de la Corte de Apelaciones de Santiago (2019): Corte Suprema, 22 abril 2019.

Nutriplus Alimentación y Tecnología S.A. con Junta Nacional de Auxilio Escolar y Becas (2019): Corte de Apelaciones de Santiago, 19 junio 2019.

Clínica Colonial S.A., con Fondo Nacional de Salud (2013): Tribunal de la Contratación Pública, 21 agosto 2014.

Dictamen No 56.391 (2008): Contraloría General de la República, 28 de noviembre de 2008.

Dictamen No 53.520 (2008): Contraloría General de la República, 13 de noviembre de 2008.

Dictamen N 38.794 (2009): Contraloría General de la República, 21 de julio de 2009.

Dictamen No 17.016 (2013): Contraloría General de la República, 18 de marzo de 2013.

Dictamen No 10.448 (2014): Contraloría General de la República, 11 de febrero de 2014.

Dictamen No 14.236 (2018): Contraloría General de la República, 7 de junio de 2018.

Dictamen N 7 (2019): Contraloría General de la República, 26 de marzo de 2019.

Dictamen No 42.621 (2007): Contraloría General de la República, 21 de septiembre de 2007.

Dictamen N 81.434 (2015): Contraloría General de la República, 13 de octubre de 2015.

Dictamen N 76.516 (2012): Contraloría General de la República, 10 de diciembre de 2012.

Dictamen No 46.532 (2000): Contraloría General de la República, 4 de diciembre de 2000.

Dictamen No 61.442 (2012): Contraloría General de la República, 3 de octubre de 2012.

Dictamen N 71.748 (2012): Contraloría General de la República, 19 de noviembre de 2012.

Dictamen N 10.172 (2017): Contraloría General de la República, 23 de marzo de 2017. 
Dictamen N 8.805 (2016): Contraloría General de la República, 3 de febrero de 2016.

Dictamen N 46.532 (2000): Contraloría General de la República, 4 de diciembre de 2000.

Dictamen N²6.006 (2016): Contraloría General de la República, 8 de abril de 2016.

Dictamen Nº 8.805 (2016): Contraloría General de la República, 3 de febrero de 2016.

Dictamen N 68.458 (2012): Contraloría General de la República, 31 de octubre de 2012.

Dictamen No 45.278 (2000): Contraloría General de la República, 24 de noviembre de 2000.

Dictamen N 34.434 (2000): Contraloría General de la República, 8 de septiembre de 2000.

Dictamen No 52.018 (2007): Contraloría General de la República, 19 de noviembre de 2007.

Dictamen No 87.444 (2015): Contraloría General de la República, 4 de noviembre de 2015.

Dictamen N 45.278 (2000): Contraloría General de la República, 24 de noviembre de 2000.

Dictamen N 23.348 (2010): Contraloría General de la República, 4 de mayo de 2010.

Dictamen N 50.123 (2011): Contraloría General de la República, 9 de agosto de 2011.

Dictamen Nº 81.434 (2015): Contraloría General de la República, 13 de octubre 2015.

Dictamen N 8.805 (2016): Contraloría General de la República, 3 de febrero de 2016.

Dictamen No 68.458 (2012): Contraloría General de la República, 31 de octubre de 2012.

Dictamen N² 2453 (2018): Contraloría General de la República, 22 de enero de 2018.

Dictamen Nº 40.452 (2006): Contraloría General de la República, 29 de agosto de 2006. 